passed behind the heart to reach the IVC (Figure 1). A ringed polytetrafluoroethylene (Gore-Tex) conduit was used to mitigate against compression by the heart. Warfarin was given for 6 months postoperatively with a goal international normalized ratio of 1.5 to 2.0 , followed by aspirin therapy alone. One year after discharge, an echocardiogram showed unobstructed conduit flow.

\section{DISCUSSION}

Takedown of a Glenn shunt has been reported, but it is uncommon. In particular, there is a paucity of information on take-down and reconstruction of a left-sided Glenn in patients with atrial situs solitus. ${ }^{1,2}$ Coloni and colleagues ${ }^{3}$ describe using ringed and non-ringed PTFE grafts, as well as a conduit made from autologous or bovine pericardium to reconstruct the SVC and left brachiocephalic veins. Mahesh and Ratnatunga ${ }^{4}$ reported reconstruction of the SVC with aortic and pulmonary homograft in patients with SVC occlusion due to benign or malignant pathology.

\section{CONCLUSIONS}

The technique we have described is most relevant in the pediatric population, in whom chest wall compression of an anteriorly located conduit used for reconstruction of the left SVC has the greatest potential to be problematic. The major disadvantage to the technique we describe is the potential for thrombosis in the relatively long, small-caliber PTFE (Gore-Tex) graft. As has been our practice with patients undergoing Fontan by the extracardiac conduit technique, we plan to anticoagulate with warfarin (international normalized ratio, $\sim 2.0$ ) for approximately 6 months and then transition to aspirin.

The authors thank Dr Irving Tessler for providing the medical illustration.

\section{References}

1. Pacifico AD, Kirklin JW. Takedown of cava-pulmonary artery anastomosis (Glenn) during repair of congenital cardiac malformations. $J$ Thorac Cardiovasc Surg. 1975;70:272-7.

2. Rohmer J, Quaegebeur JM, Brom GA. Takedown and reconstruction of cavopulmonary anastomosis. Ann Thorac Surg. 1977;23:129-34.

3. Venuta F, Rendina EA, Coloni GF. Surgery of the superior vena cava: resection and reconstruction. Thoracic Techniques. 19 Oct 2009. Available at: http://www.ctsnet. org/sections/clinicalresources/thoracic/expert_tech-6.html. Accessed March 23, 2011 .

4. Mahesh B, Ratnatunga C. Superior vena cava reconstruction with homograft conduit under circulatory arrest. Asian Cardiovasc Thorac Ann. 2007;15: $345-7$.

\title{
Venovenous extracorporeal membrane oxygenation using a single cannula in patients with pulmonary hypertension and atrial septal defects
}

\author{
Jeffrey Javidfar, MD, ${ }^{a}$ Daniel Brodie, MD, ${ }^{\mathrm{b}}$ Joshua Sonett, MD, ${ }^{\mathrm{a}}$ and Matthew Bacchetta, MD, ${ }^{\mathrm{a}}$ New York, \\ NY
}

Adults with unrepaired congenital septal defects are at risk of developing Eisenmenger's syndrome, characterized by pulmonary hypertension and right ventricular failure. If such patients fail medical therapy and acute on chronic cardiopulmonary failure develops, they can be supported with venoarterial extracorporeal membrane oxygenation $\left(\right.$ ECMO) until they recover or receive a transplant. ${ }^{1}$

\footnotetext{
From the Divisions of Cardiothoracic Surgery a and Pulmonary, Allergy, and Critical Care Medicine, ${ }^{\mathrm{b}}$ Columbia University Medical Center, New York, NY.

Disclosures: Authors have nothing to disclose with regard to commercial support.

Received for publication May 2, 2011; revisions received Sept 18, 2011; accepted for publication Oct 21, 2011; available ahead of print Dec 5, 2011.

Address for reprints: Jeffrey Javidfar, MD, Columbia University Medical Center, Herbert Irving Pavilion, 161 Fort Washington Ave, Suite 301, New York, NY 10032 (E-mail: jj2316@ columbia.edu).

J Thorac Cardiovasc Surg 2012;143:982-4

$0022-5223 / \$ 36.00$

Copyright (C) 2012 by The American Association for Thoracic Surgery

doi:10.1016/j.jtcvs.2011.10.061
}

Standard approaches to venoarterial ECMO require both venous and arterial cannulation. In addition to requiring a second cannula, without a concomitant ancillary antegrade catheter, peripheral arterial cannulation is associated with the risk of limb ischemia.

The Avalon Elite Bicaval Dual Lumen catheter (Avalon Laboratories, LLC, Rancho Domingez, Calif) allows for adult venovenous ECMO through a single cannulation site. $^{2}$ The catheter has a right atrial infusion port that can take advantage of the congenital atrial septal defect (ASD) (Figure 1) and shunt oxygenated blood into the left side of the heart while the other lumen drains the venae cavae. ${ }^{2}$ Camboni and colleagues ${ }^{3}$ confirmed right to left atrial shunting of oxygenated blood when using this cannula for ECMO in sheep. We present the novel use of this catheter to provide venovenous ECMO with a physiologic shunt and right ventricular decompression without an arterial cannula. 


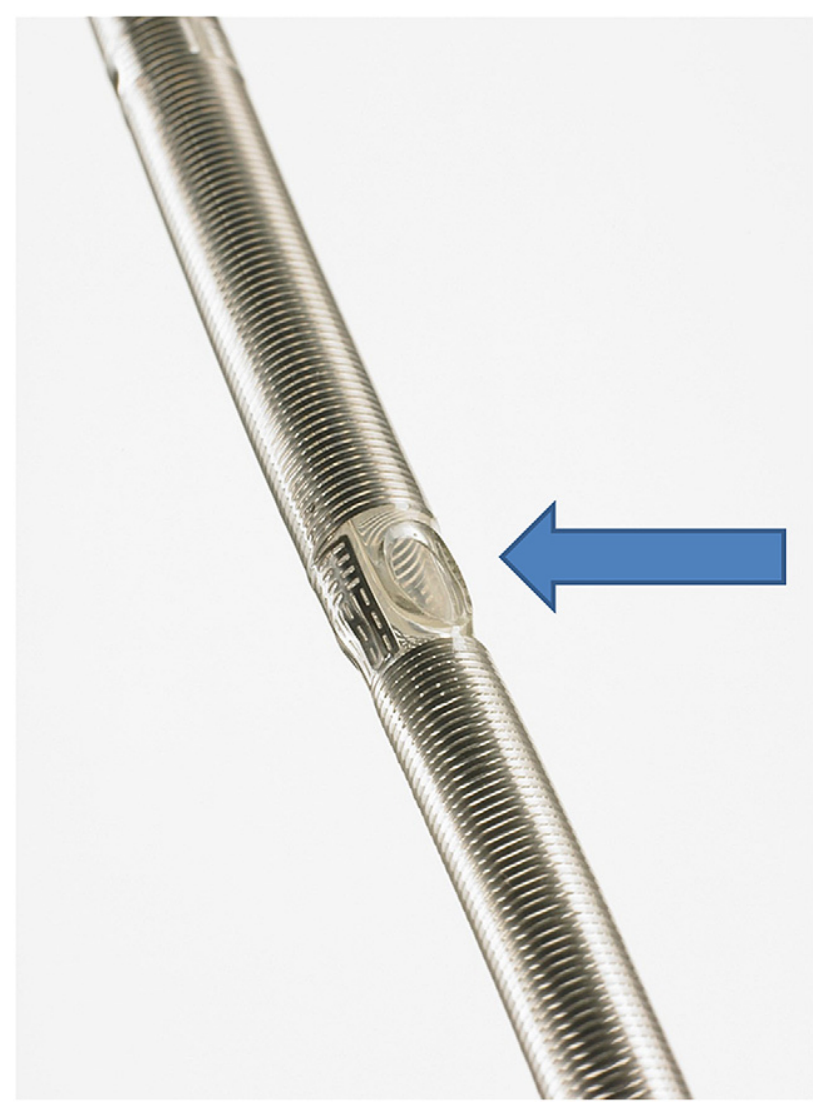

FIGURE 1. A dual lumen ECMO catheter with a right atrial infusion port (blue arrow).

\section{CLINICAL SUMMARY}

Two adults with secundum ASDs and Eisenmenger's syndrome were selected for this modified cannulation technique after conventional medical therapy failed to treat their acute decompensations. Both patients were on the transplant list. Patient 1 was admitted to the intensive care unit (ICU) in respiratory failure with elevated pulmonary artery pressures. After another pulmonary hypertensive crisis, cardiopulmonary arrest occurred and she was taken to the operating room for emergency ECMO cannulation. Patient 2 presented with hemoptysis refractory to embolization of aortopulmonary collaterals. On admission, she had suprasystemic pulmonary artery pressures. While on inhaled nitric oxide in the ICU, she had ongoing hemoptysis and an arterial oxygen desaturation to $60 \%$. She progressed to respiratory failure and was placed on ECMO as a bridge to transplant.

A 23F Avalon Elite (Avalon Laboratories, LLC) was inserted into the right internal jugular vein of each patient under standard image guidance. ${ }^{2}$ Transesophageal echocardiogram was used to ensure that the cannula's right atrial infusion port was positioned with flows directed across the ASD (Figure 2). Each cannula was attached to a standard venovenous ECMO circuit. Improvements in pulmonary artery pressure and right ventricular unloading were confirmed on transesophageal echocardiogram before securing the catheter in place. Afterward, the patients were managed on ECMO according to established low-dose anticoagulation and lung-protective ventilation protocols. ${ }^{4}$

\section{RESULTS}

Adequate flows, good gas exchange, improved hemodynamics, and ventricular decompression were immediately recorded (Table 1). Both patients had an uncomplicated ECMO course. Patient 1 recovered after resting on venovenous ECMO for 23 days. She remained neurologically intact despite her cardiopulmonary arrest and was weaned from the ventilator. She was discharged from the ICU and lived 4 months before dying of an episode of acute pneumonia. Patient 2 was extubated on ECMO shortly after cannulation. After 6 days on venovenous ECMO, she was bridged to double lung transplantation with ASD repair. The patient did not require ECMO posttransplant. She was discharged from the hospital with improved right heart function and has returned to normal activities.

\section{CONCLUSIONS}

Venovenous ECMO with the Avalon Elite can be used as a bridge to recovery or transplantation in adults with ASDs presenting with exacerbations of chronic lung disease and right heart failure. Both patients were extubated and ultimately weaned from mechanical circulatory support. For patient 2, the benefits of early extubation while still on ECMO included markedly less sedation requirements, resumption of traditional enteral intake, increased mobility, participation in physical therapy, and avoidance of a ventilatory associated pneumonia.

The unique physiology of these patients, including the markedly elevated pulmonary artery pressures, requires that oxygenated blood reach the left side of the heart. This was accomplished with one cannula by directing flow across the ASD, thereby creating an oxygenated physiologic right to left shunt. This form of venovenous ECMO offers patients improved oxygenation while partially unloading the right side of the heart, without the complications associated with standard peripheral arterial cannulation.

Although this technique was performed in only 2 patients, these results show that the concept is feasible. The single-site approach mimics venoarterial ECMO through venovenous cannulation, but requires a preexisting congenital atrial defect. Both in patients with Eisenmenger's syndrome who do not have an ASD and in other patients with severe pulmonary artery hypertension, an atrial blade septostomy should be considered. ${ }^{3,5}$ By percutaneously 


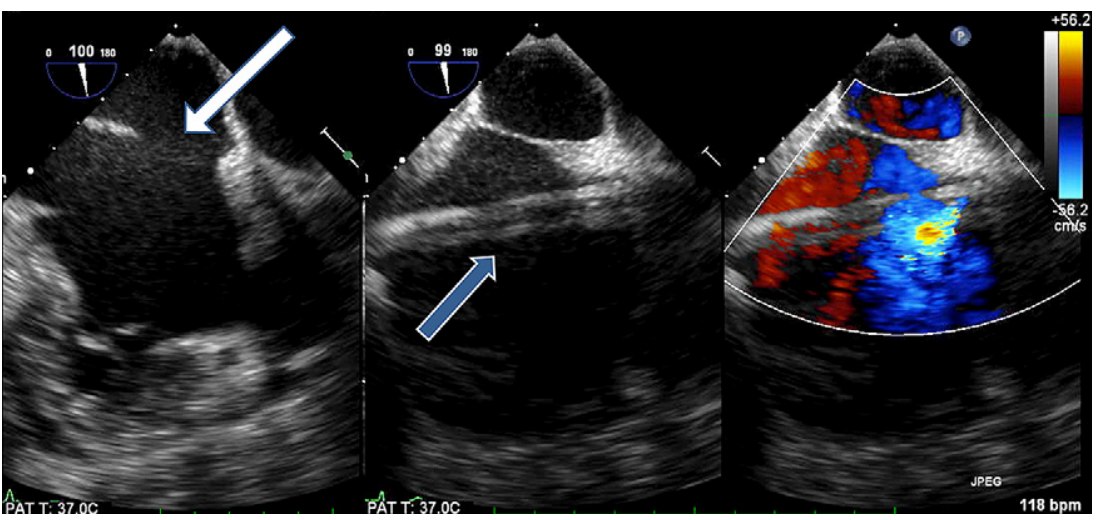

FIGURE 2. The right atrial infusion port (blue arrow) shunts oxygenated blood across the ASD (white arrow).

TABLE 1. Patients with congenital pulmonary hypertension

\begin{tabular}{|c|c|c|c|c|c|c|}
\hline \multicolumn{2}{|c|}{ Demographics } & \multicolumn{3}{|c|}{ Respiratory parameters* } & \multicolumn{2}{|c|}{ Cannula performance measurements } \\
\hline Patient 1 & & & Pre-ECMO & During ECMO & & \\
\hline Age & $41 \mathrm{y}$ & $\mathrm{PAO}_{2}: \mathrm{FIO}_{2}$ ratio & 36 & & & \\
\hline \multirow[t]{7}{*}{ Body mass index } & 14 & $\mathrm{pH}$ & 7.43 & 7.48 & Cannula size & $23 \mathrm{~F}$ \\
\hline & & $\mathrm{PCO}_{2}(\mathrm{~mm} \mathrm{Hg})$ & 52 & 46 & Days of pre-ECMO intubation & 0 \\
\hline & & $\mathrm{PAO}_{2}(\mathrm{~mm} \mathrm{Hg})$ & 36 & 79 & Duration of ECMO support (d) & 23 \\
\hline & & $\mathrm{SAO}_{2}$ & $64 \%$ & $92 \%$ & Median ECMO flow rates (L/min) & $2.4(2.1-2.6)$ \\
\hline & & Systemic blood pressure (mm $\mathrm{Hg}$ ) & Arrest & $125 / 55$ & pRBC transfused (units) $\ddagger$ & 7 \\
\hline & & $\begin{array}{l}\text { Pulmonary artery pressure } \\
\quad(\mathrm{mm} \mathrm{Hg}) \S\end{array}$ & $100 / 66$ & $58 / 17$ & Platelets transfused $(\mathrm{mL}) \ddagger$ & 643 \\
\hline & & $\begin{array}{l}\text { Evidence of right ventricular } \\
\text { decompression on } \\
\text { echocardiogram }\end{array}$ & No & Yes & EBL during cannulation $(\mathrm{mL})$ & 25 \\
\hline Patient $2 \dagger$ & & & Pre-ECMO & During EMCO & & \\
\hline Age & $22 \mathrm{y}$ & $\mathrm{PAO}_{2}: \mathrm{FIO}_{2}$ ratio & 60 & & & \\
\hline \multirow[t]{7}{*}{ Body mass index } & 17 & $\mathrm{pH}$ & 7.36 & 7.38 & Cannula size & $23 \mathrm{~F}$ \\
\hline & & $\mathrm{PCO}_{2}(\mathrm{~mm} \mathrm{Hg})$ & 41 & 41 & Days of pre-ECMO intubation & 0.5 \\
\hline & & $\mathrm{PAO}_{2}(\mathrm{~mm} \mathrm{Hg})$ & 60 & 108 & Duration of ECMO support (d) & 6 \\
\hline & & $\mathrm{SAO}_{2}$ & $75 \%$ & $98 \%$ & Median ECMO flow rates (L/min) & $2.6(2.3-2.8)$ \\
\hline & & Systemic blood pressure $(\mathrm{mm} \mathrm{Hg})$ & $92 / 40$ & $133 / 57$ & pRBC transfused (units) $\ddagger$ & 0 \\
\hline & & $\begin{array}{l}\text { Pulmonary artery pressure } \\
\quad(\mathrm{mm} \mathrm{Hg}) \S\end{array}$ & $116 / 66$ & $35 / 17$ & Platelets transfused $(\mathrm{mL}) \ddagger$ & 0 \\
\hline & & $\begin{array}{l}\text { Evidence of right ventricular } \\
\text { decompression on } \\
\text { echocardiogram }\end{array}$ & No & Yes & EBL during cannulation $(\mathrm{mL})$ & 50 \\
\hline
\end{tabular}

$\mathrm{PAO}_{2}$, Arterial oxygen tension; $\mathrm{FlO}_{2}$, fraction of inspired oxygen; $\mathrm{SAO}_{2}$, arterial oxygen saturation; $p R B C$, packed red blood cells; $E B L$, estimated blood loss. *Median values. $\dagger$ Pre-lung transplant values. $\ddagger$ During entire ECMO run. $\S$ Both patients experienced a pulmonary hypertensive crisis.

creating an ASD, a surgeon can offer venovenous ECMO with a physiologic shut and right ventricular decompression to larger patient populations, while using a single cannulation site.

\section{References}

1. Belohlavek J, Rohn V, Jansa P, et al. Veno-arterial ECMO in severe acute right ventricular failure with pulmonary obstructive hemodynamic pattern. J Invasive Cardiol. 2010;22:365-9.
2. Javidfar J, Brodie D, Wang D, et al. Use of bicaval dual-lumen catheter for adult venovenous extracorporeal membrane oxygenation. Ann Thorac Surg. 2011;91:1763-9.

3. Camboni D, Akay B, Sassalos P, et al. Use of venovenous extracorporeal membrane oxygenation and an atrial septostomy for pulmonary and right ventricular failure. Ann Thorac Surg. 2011;91:144-9.

4. Brodie D, Bacchetta M. Extracorporeal membrane oxygenation for ARDS in adults. N Engl J Med. 2011;365:1905-14.

5. Seib PM, Faulkner SC, Erickson CC, et al. Blade and balloon atrial septostomy for left heart decompression in patients with severe ventricular dysfunction on extracorporeal membrane oxygenation. Catheter Cardiovasc Interv. 1999;46: $179-86$. 